\title{
The effect of frontoparietal lesions on stability and tremor in the finger
}

\author{
J D COLE, H I PHILIP, E M SEDGWICK \\ From the Wessex Neurological Centre, Southampton, UK
}

SUMMARY Assessment of stability and tremor in the fingers in patients with unilateral frontoparietal lesions involved the task of attempting to keep the finger still on a typewriter key connected to a strain gauge.

In patients with no or minimal pyramidal motor signs and/or cortical sensory signs, the amplitudes of tremor compared with normal controls showed that the contralateral side was not significantly different from normal but that the ipsilateral side was significantly less stable than normal. In normal subjects the tremor seen during the task, and determined from the fast Fourier transform, (FFT), showed a peak at $1-3 \mathrm{~Hz}$ and a gradual falling off to background levels by $6 \mathrm{~Hz}$ or so. In patients with spasticity, weakness and sensory impairment there was an additional peak of tremor seen at 6-7 Hz ipsilateral to the cerebral lesion.

Pyramidal deficits, due to lesions of the frontoparietal cortex and subcortical area, are traditionally assessed clinically by defects in power, increase in tone and hyperreflexia. However, early in the course of a disease or when the pathology is minimal these classical signs may be difficult to elicit or even be absent at presentation, as for example in mature onset epilepsy. The present investigation was designed to observe if such patients had any asymmetry in the performance of tasks involving movement of their fingers. The effect in patients with established pyramidal lesions was also investigated.

A simple test was chosen in which the subjects were asked to maintain the index finger stable on a typewriter key connected to a strain gauge measuring forces of between 100 and $5 \mathrm{~g}$ and with a total movement of less than $1 \mathrm{~mm}$. At these extremes of minimal applied force and maximal accuracy motor control of the finger was stressed.

Some preliminary results from the present work have been communicated to the Physiological Society..$^{12}$

Address for reprint requests: Dr J D Cole, Wessex Neurological Centre, Southampton SO9 4XY, UK.

Received 15 March 1988.

Accepted 13 May 1988

\section{Methods}

\section{Instrumentation}

Into the surface of a flat box was set a typewriter key connected to a strain gauge. The maximum movement of the gauge was less than a millimetre when the sensitivity was at $100 \mathrm{~g}$ for full deflection and less than $0.1 \mathrm{~mm}$ for a sensitivity of $10 \mathrm{~g}$, that is, the task was essentially isometric. The strain gauge was supplied from a regulated - 5V supply and the output was applied to the inputs of a differential amplifier, in order to obtain a "single-ended" output voltage. The output from the differential amplifier was applied to the input of a variable gain inverting amplifier. This permitted the sensitivity of the system to be varied electronically without requiring any adjustment to the strain gauge.

The output of the variable gain amplifier was applied directly to a moving coil milliammeter mounted on the front panel of the instrument to provide the patient with visual feedback. The milliammeter had a scale from 1 to 10 which was $8 \mathrm{~cm}$ across and so at a distance of around $50 \mathrm{~cm}$ from the eyes a full scale deflection subtended approximately $9 \cdot 2^{\circ}$ of the visual arc. The output was passed via a low pass filter ( $47 \mathrm{~ms}$ time constant) to filter out any $50 \mathrm{~Hz}$ noise. In addition to the meter on the front panel, another separate one was provided in order to assess the effects of varying degrees of visual feedback on finger stability for the same sensitivities on the strain gauge. This second milliammeter was mounted above and a little behind the main instrument but had a similar dial to it. The dial face was slightly larger $(10 \mathrm{~cm}$ across) and it subtended an angle of approximately $5.73^{\circ}$ to the visual field. When this was used the main instruments dial was covered. There was a phase lag between movement of the strain gauge and of the needles of the milliammeters of $0.7 \mathrm{~s}$ 
for a full deflection and $\mathbf{0 . 2 5} \mathrm{s}$ for half maximal deflection of the needle.

The output from the instrument was passed to a differential amplifier of high output impedance so that the output current from the amplifier was proportional to the input voltage. The output from this amplifier was then applied to the games paddle inputs of an APPLE II computer which had been calibrated using known values of current; that is, effectively the system behaved as an analogue input to the computer. The instrument was calibrated by measuring the voltage output when known weights were placed on the typewriter key. The output was expressed as voltage vs grams weight. The data were stored initially on a Racal store 4 track tape recorder for subsequent off line analysis. In addition a simple X-Y plot of the subjects performance was made with a Bryans 26000.

\section{Data processing}

The data were processed using an APPLE II computer programmed in UCSD PASCAL. The data were first entered and stored on a floppy disc, as a series of data points, 768 points representing $24 \mathrm{~s}$ of real time. The raw data were then processed, after an initial top frequency filter at $20 \mathrm{~Hz}$, with a fast Fourier transform (FFT) program. In each case $24 \mathrm{~s}$ were analysed by performing a FFT on $8 \mathrm{~s}$ of data three times sequentially. Memory was independent of the FFT program and so did not reduce resolution of successive FFTs. Then the FFTs from each of the 8 s periods were added together to give the result plotted. A Hanning window was used to reduce any zero frequency artifact. ${ }^{3}$

The results were then plotted out with a dot matrix printer (Apple Silentype or Apple Imagewriter) in four different formats; raw data, normalised spectrum, histogram and absolute spectrum. The raw data was a plot of the variations in key pressure over the first $8 \mathrm{~s}$ of measurement time. The normalised spectrum was a plot of the amplitude vs frequency in the range 0 to $16 \mathrm{~Hz}$ with the greatest amplitude expanded to full scale. A $20 \mathrm{~Hz}$ top filter with plots of up to $16 \mathrm{~Hz}$ was close to the Nyqvist frequency, which suggests that frequency analysis should be only to half the frequency resolution of the FFT, (in this case $32 \mathrm{~Hz}$ ). A filter of $20 \mathrm{~Hz}$ on the incoming signal rather than $16 \mathrm{~Hz}$ was chosen to reduce the effect of top end bias. This does mean that theoretically tremor from $12-16 \mathrm{~Hz}$ could be reflected from $16-20 \mathrm{~Hz}$. However there was little tremor at these frequencies and it was discounted in subsequent analysis. The histogram was obtained by averaging the normalised spectrum over each $0.5 \mathrm{~Hz}$ interval and plotting the histogram of the resulting averages. The absolute spectrum was a direct plot of the results obtained from the FFT program and were used to compare the absolute amount of tremor present in different subjects.

\section{Procedure}

The subject was positioned at a table with the instrument before him. He was shown how to position the index finger on the typewriter key with the rest of the hand placed on the surface of the instrument's flat top surface. He was asked to keep the needle of the milliammeter as near to the required number as possible using visual feedback to maintain accuracy. The forces to be maintained were $0.049 \mathrm{~N},(5 \mathrm{~g} . \mathrm{wt}$.), to $0.78 \mathrm{~N}$, (80 g.wt.) on sensitivities of $10 \mathrm{~g}$ and $100 \mathrm{~g}$ respectively. Immediately the subject was familiar with the task recording began. Performance of the task was only possible with small deviations away from the required position which for want of a better word have been termed tremor. In the present work the term perturbation will be used to describe them singly and tremor collectively, although the terms are nearly interchangeable. No time to learn to improve accuracy was given.

Each run at a given sensitivity lasted approximately $90 \mathrm{~s}$ with simultaneous recording on tape and X-Y plot. In those runs in which the subject was asked to do the task with eyeso shut no such warning was given. Thus at the end of a $90 \mathrm{~s}$

Table 1 Clinical details of patients in Group 1

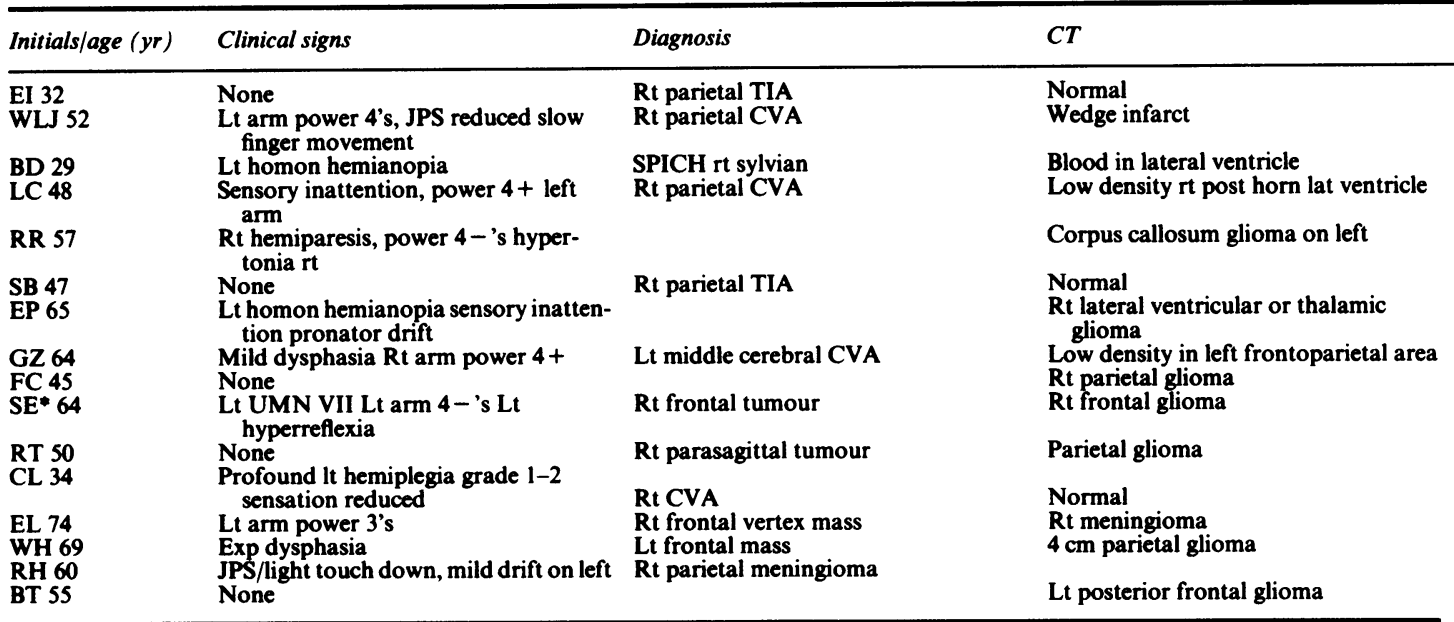

* evidence of midline shift on CT scan SPICH spontaneous intracranial haemorrhage CVA cerebrovascular accident TIA transient ischaemic attack. 
Table 2 Clinical details of patients in Group 2

\begin{tabular}{|c|c|c|c|}
\hline Initials/age (yr) & Signs & Diagnosis & Midline shift on $C T$ \\
\hline JM 55 & $\begin{array}{l}\text { Lt arm grade } 4 \text { weakness and reduced } \\
\text { sensation }\end{array}$ & Rt parietal glioma & Gross \\
\hline TM 63 & $\begin{array}{l}\text { Rt power 4's JPS light touch down } \\
\text { inattention }\end{array}$ & Lt parieto-occipital glioblastoma & Minimal \\
\hline $\begin{array}{l}\text { GM } 72 \\
\text { EG } 51 \\
\text { NB } 78 \\
\text { AT } 54 \\
\text { MM } 50 \\
\text { CL } 34\end{array}$ & $\begin{array}{l}\text { Lt power } 4 \text { 's tone and reflexes up } \\
\text { Finger power } 4 \mathrm{rt} \\
\text { Mild it hyperreflexia } \\
\text { None, (slow fast finger movement rt) } \\
\text { Lt shoulder weakness wrist power } 4 \text { 's } \\
\text { Lt hemiparesis profound JPS, touch } \\
\text { down }\end{array}$ & $\begin{array}{l}\text { Rt frontal mass } \\
\text { Lt parietal CVA } \\
\text { Old rt parietal CVA } \\
\text { Lt frontal glioma } \\
\text { Rt parietal meningioma } \\
\text { Rt parietal CVA }\end{array}$ & $\begin{array}{l}\text { Yes } \\
\text { None } \\
\text { None } \\
\text { Gross } \\
\text { Minimal } \\
\text { None }\end{array}$ \\
\hline $\begin{array}{l}\text { GG } 65 \\
\text { WB 73 } \\
\text { RR } 32\end{array}$ & $\begin{array}{l}\text { Lt arm power } 4 \text { 's } \\
\text { Lt arm power } 4 \text { 's } \\
\text { Sensory inattention }\end{array}$ & $\begin{array}{l}\text { Right frontal secondary } \\
\text { Rt parietal mass } \\
\text { Posterior parietal neuroectodermal } \\
\text { mass }\end{array}$ & $\begin{array}{l}\text { Minimal } \\
\text { Minimal } \\
\text { Minimal }\end{array}$ \\
\hline $\begin{array}{l}\text { JR } 34 \\
\text { IL } 55\end{array}$ & $\begin{array}{l}\text { Post parietal signs lt } \\
\text { None }\end{array}$ & $\begin{array}{l}\text { Rt parietal neuroectodermal tumour } \\
\text { Lt parasagittal meningioma }\end{array}$ & $\begin{array}{l}\text { Minimal } \\
\text { Minimal }\end{array}$ \\
\hline
\end{tabular}

period with the eyes open they were asked to continue with their eyes shut.

All of the results from this work were evident from visual observation of the XY plots. However, this technique did not allow for quantitative or statistical analysis and so fast Fourier transform analysis was also used. The two techniques are complimentary.

Twenty-four seconds of the taped data were analysed with the fast Fourier transform. Comparison of the taped record

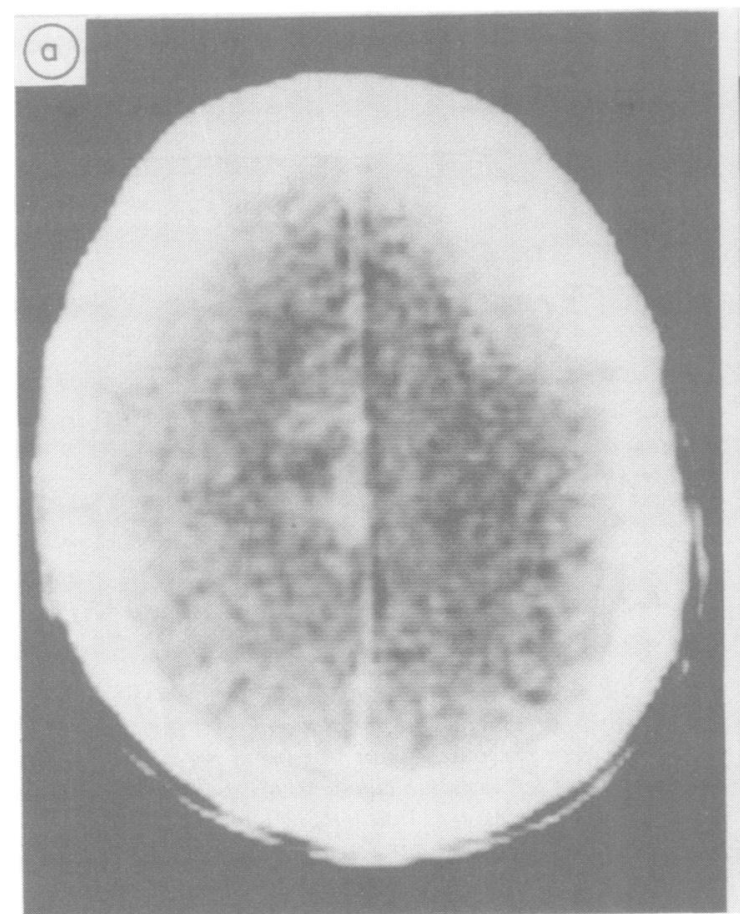

with the X-Y plot was made to ensure that the $24 \mathrm{~s}$ period was representative of the record as a whole. The tremor profile in terms of how much occurred at given frequencies was determined by visual analysis of the FFT printout. Quantitative analysis of the tremor was estimated by taking the frequency at which most tremor occurred and measuring the amount of tremor at this frequency calculated over the $0.5 \mathrm{~Hz}$ period at this maximum from the histogram. This was expressed in grams weight. The amplitude density of the FFT

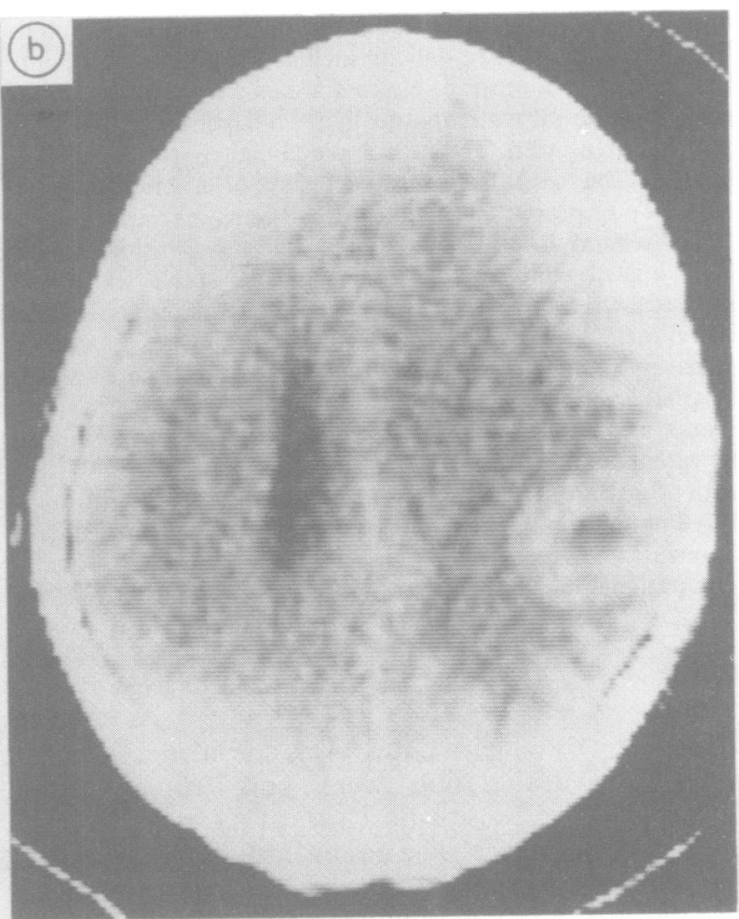

Fig 1 CT scans of two patients in the present study. (a) RT right parasagittal glioma. On presentation with mature onset epilepsy the lesion was only equivocally present. This is the second scan several months later, when pyramidal signs were present. This patient was in group 1. (b) JR right parietal neuroectodermal cyst. Patient had posterior parietal signs and was in group 2. 
expressed tremor as a sum of the amplitude of each perturbation and the number of occurrences of tremor at each frequency. It therefore could not distinguish a single large perturbation say at $1 \mathrm{~Hz}$ from ten smaller ones at the same frequency but with one tenth the amplitude. To ensure the record used for FFT analysis was representative the XY plotter was used. However, it also served another purpose. The average amplitude of each perturbation during each run was measured directly from the XY plot. At sensitivities of both 10 and $100 \mathrm{~g}$ wt the XY plotter's output was set at 400 $\mu \mathrm{V} \mathrm{cm}^{-1}$. The amplitude of perturbations was read directly off the vertical axis of the plotter for sensitivity of $100 \mathrm{~g} \mathrm{wt}$. and read off and then scaled down by a factor of ten for $10 \mathrm{~g} \mathrm{wt}$.

To give some estimate of the frequency of perturbation a simple turn analysis was employed. A line was drawn through the midpoint of the XY plots horizontal axis. The number of times that the record then crossed the midpoint in $7.5 \mathrm{~s}$ was counted and this gave the turn count which was expressed in turns per second.

\section{Patients}

The patients had been admitted for assessment and treatment. Prior to admission they had been examined by a consultant neurologist and subsequently by a neurological senior registrar or registrar. In addition before the procedure one of us, (JDC), would re-examine them.

In the first group of 15 patients neurological disability was relatively slight or absent altogether, (table 1). In half the patients there was a mild pyramidal weakness (MRC scale grade 4) contralateral to the cortical lesion, with some hyperreflexia. Sensory deficits included reductions in light touch or proprioception. No modalities were absent. These patients were all walking and living independently. In five patients signs were absent completely, their presentations having been with late onset epilepsy or a brief loss of sensation or power, so called transient ischaemic attacks.

The second group of 13 patients were those with classical neurological signs of pyramidal deficit, (table 2). They showed increase in tone and reflexes contralaterally to the lesion with varying degrees of weakness. Some had presented relatively soon before testing, others were some time after the original event. The pathologies included cerebrovascular events and cerebral tumours. Some patients were studied repeatedly to investigate the alteration in their finger stability with progression of their disease or to see the effect operation.

All patients gave their informed consent for the investigation which had received hospital ethical committee approval. The patients had also had computed tomography (CT) for diagnosis, except a minority of those with classical stroke.

\section{Results}

The criteria by which a patient was considered to have a frontoparietal lesion were both clinical and radiological. In those with classical pyramidal signs and/or CT evidence of a lesion around the central sulcus this was not a problem. In those without a structural lesion the presence of focal epilepsy or transient signs or symptoms in an arm or leg were taken. An effect on finger stability was seen only with larger frontal lesions more often causing midline shift on CT scan but with smaller lesions in the area of the central sulcus. Two examples of frontoparietal lesions in the patients are shown in fig 1.

(a) patients with minimal neurological signs.

The procedure was performed at $100 \mathrm{~g}$ and at 5 to $10 \mathrm{~g}$, with eyes open and shut. There was no significant right:left difference in a sample of 29 normal controls. The FFT profile of the tremor during the task showed a peak at $1-3 \mathrm{~Hz}$ and a gradual tailing off of tremor to background levels by about $6 \mathrm{~Hz}$. No additional peaks

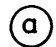

(i)

(ii)

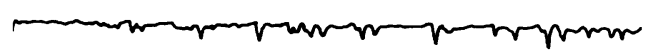

(iii)

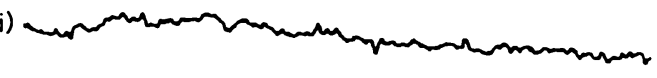

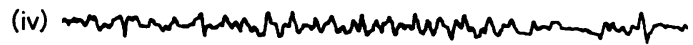<smiles></smiles>

(i)

(ii)

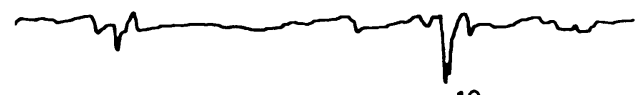

(iii)

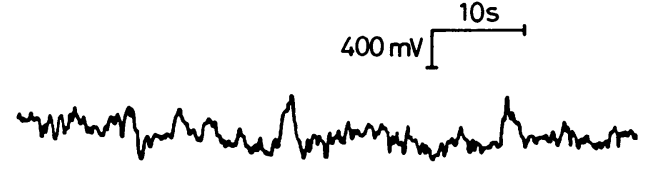

(iv)

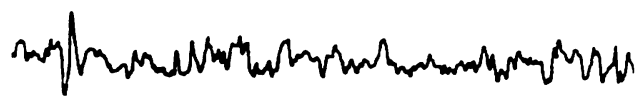

Fig $2 X Y$ plots of stability in index fingers in two patients. (a) patient 1 had had a right parietal transient ischaemic attack one week previously, with 30 mins of parasthesia and weakness in the left arm. No clinical signs. Sensitivity $25 \mathrm{gV}-1$. (i) left index eyes shut, (ii) left index eyes open, (iii) right index eyes shut, (iv) right index eyes open. (b) patient 2 had a spontaneous intracerebral bleed 3 weeks previously in the region of the right Sylvian fissure. Residual signs were of a left homonymous hemianopia, left sensory inattention and power in the left arm 4/5. Sensitivity $25 \mathrm{gV}-1$. (i) left index eyes shut, (ii) left index eyes open, (iii) right index eyes shut, (iv) right index eyes open. 

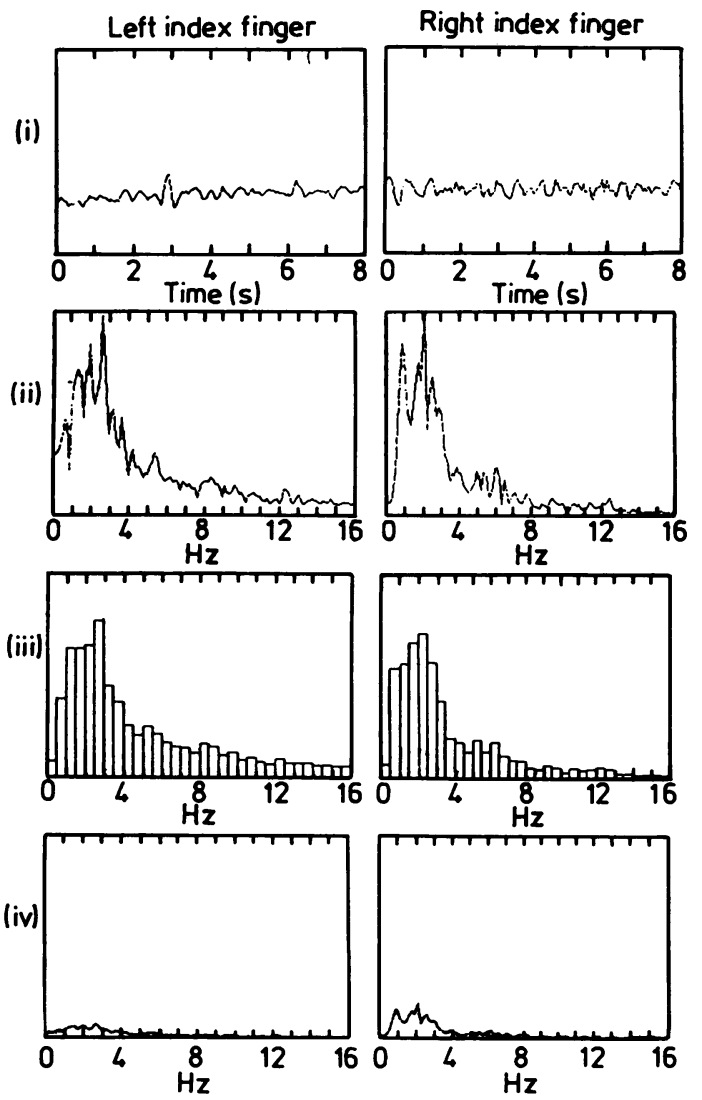

Fig 3 Fast Fourier Transform showing tremor profile of patient 1, who had had a right middle cerebral TIA one week previously. No residual clinical signs. Sensitivity $100 \mathrm{gV}-1$.

(i) FFT print our of raw data of task and tremor, (ii) FFT amplitude density. Abscissa linear scale and expanded to fill scale, right $9.31 \mathrm{~g}$, left $3.58 \mathrm{~g}$, (iii) histogram of FFT in $0.5 \mathrm{~Hz}$ epochs, linear scale, (iv) FFT amplitude density with absolute linear scale on abscissa.

were seen beyond that and in particular no peak in the range of physiological tremor.

It was an invariable finding in subjects with frontoparietal lesions that the index finger was more stable and the task performed more accurately contralateral to the unilateral cortical lesion (figs 2 and 3).

Although the amount of tremor was less than that found in the normal population contralateral to the lesion this did not reach significance. In contrast the amplitude of tremor ipsilateral to these unilateral cortical lesions was significantly increased when compared with both the results from the side contralateral to the lesion and with the results from the normal population, (table 3 and fig 4). Whilst the two populations were not aged matched there was no evidence of an age related change in stability in the task in the normal subjects. With the eyes shut these asymmetries were still present but reduced. This difference may have been introduced by the phase lag between strain gauge and milliammeter needle movement.

In only one of the patients was there evidence of a midline shift in relation to the lesion and in the case of those with transient ischaemic attacks or established stroke such a possibility does not exist. In some cases no clinical signs were elicited from the contralateral side when an ipsilateral effect on finger stability was present.

The evolution of stability in the task was followed in a single patient over months as a glioma enlarged. Initially there was no deficit with the subsequent development of mild pyramidal signs. Stability did not significantly alter over 10 months in either side, with the usual asymmetry, but on the last occasion an ipsilateral $7 \mathrm{~Hz}$ peak was present which had not been observed 10 and 6 months previously.

Additional evidence of an ipsilateral effect in unilateral lesions was revealed by the studies beforeand after-operation in four patients. On the side ipsilateral to the lesion the mean amplitude of tremor preoperatively was $10.3 \mathrm{~g}$ eyes open and $9.4 \mathrm{~g}$ with eyes

Table 3 Amplitude of tremor in patients group 1, those with minimal or no neurological signs

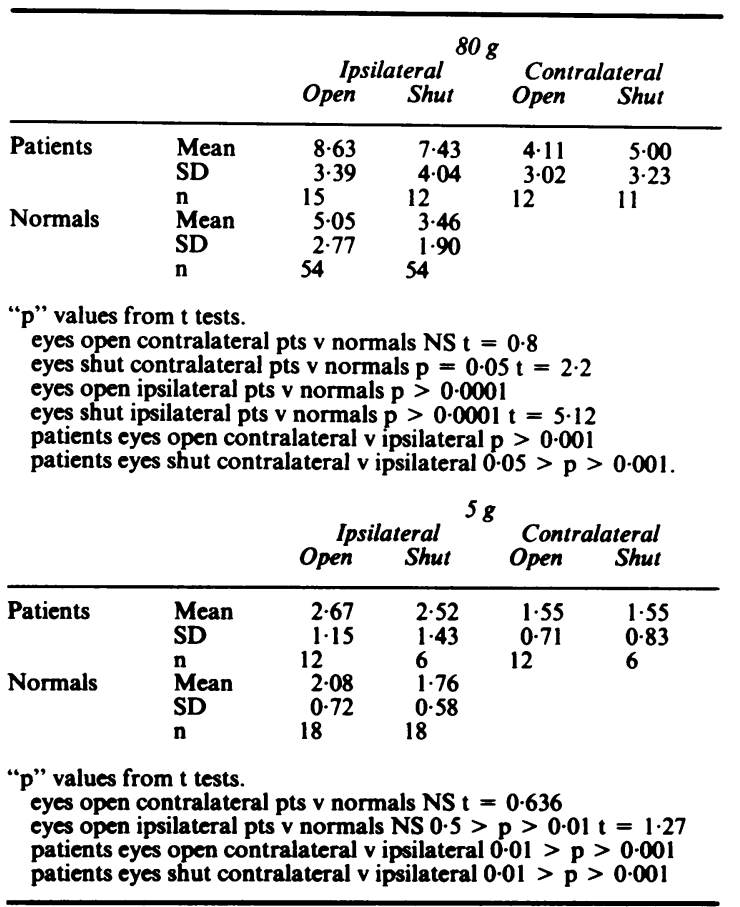




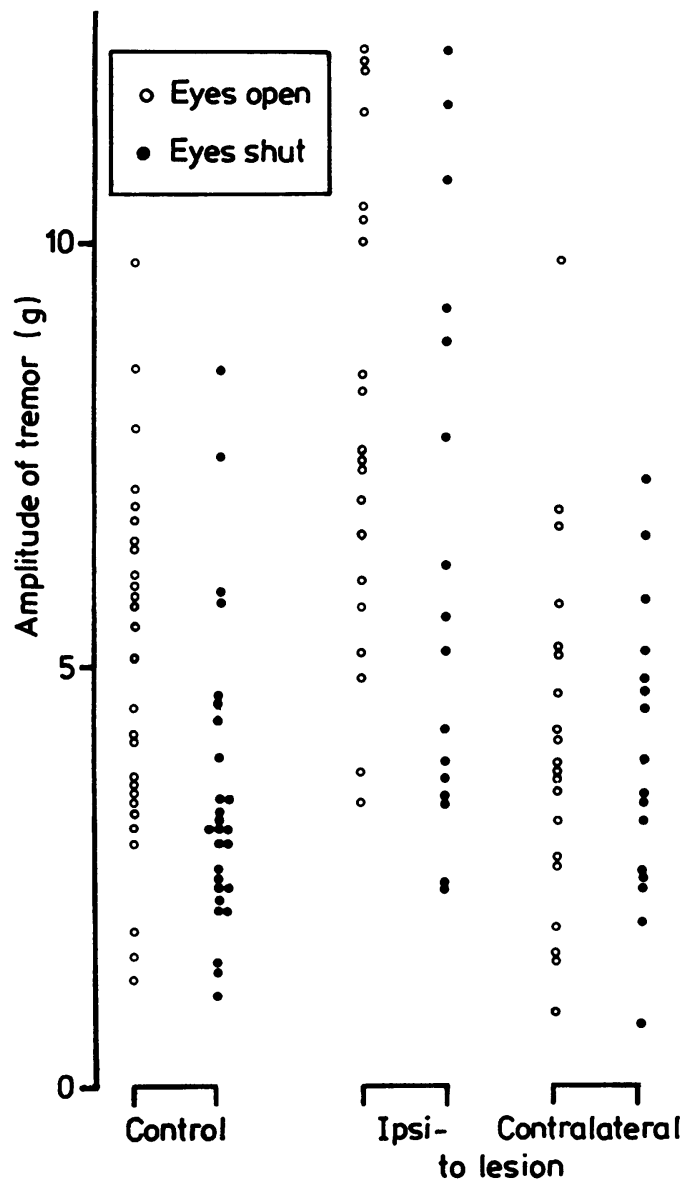

Fig 4 Graph to show the amplitudes of tremor found ipsilaterally and contralaterally to unilateral frontoparietal lesions in group 1, compared with the normal controls. Sensitivity $100 \mathrm{~g} V-1$.

shut at a sensitivity of $100 \mathrm{~g}$. After operation the figures had improved to $5.97 \mathrm{~g}$ and $4.50 \mathrm{~g}$ respectively. Surgical decompression of a unilateral lesion improved stability ipsilaterally. Unfortunately in the limb contralateral to the lesion more severe deficits were sometimes found post-operatively and so a comparison before and after operation on that side was not possible.

During the task the XY plot would be relatively stable for short periods of time and then stability would be interrupted by a perturbation (fig 2 ). The frequencies of these perturbations or turns was greater than normal ipsilaterally and less than normal contralaterally and their mean amplitude also showed a corresponding asymmetry (table 4).

A simple measure of ability to produce rapid
Table 4 (a) Analysis of mean size of perturbations in cortical lesions

\begin{tabular}{|c|c|c|c|}
\hline & & \multicolumn{2}{|c|}{ Cortical lesion } \\
\hline & & Ipsilateral & Contralateral \\
\hline $\begin{array}{l}\text { Cortical lesion } \\
\text { Normals }\end{array}$ & 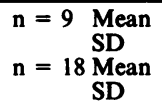 & $\begin{array}{l}0.98 \mathrm{~mm} \\
0.36 \\
0.29 \mathrm{~mm} \\
0.13\end{array}$ & $\begin{array}{l}0.44 \mathrm{~mm} \\
0.26\end{array}$ \\
\hline
\end{tabular}

" $p$ " values from unpaired $t$ tests.

Normal subjects v ipsilateral to cortical lesion $t=2.030 .1>p>0.05$. Normal subjects $v$ contralateral to cortical lesion $t=0.54 \mathrm{NS}$.

\section{(b) Analysis of frequency of turns in cortical lesions}

\begin{tabular}{|c|c|c|}
\hline & \multicolumn{2}{|c|}{ Cortical lesion } \\
\hline & Ipsilateral & Contralateral \\
\hline $\begin{array}{ll}\text { Cortical lesion } & \mathrm{n}=9 \text { Mean } \\
\text { Normals } & \mathrm{n}=18 \text { Mean }\end{array}$ & $\begin{array}{l}1.97 \\
1.78\end{array}$ & 0.98 \\
\hline
\end{tabular}

movements was produced by asking the subjects to tap rhythmically on the typewriter key as rapidly as possible. Even in those subjects with no clinical signs this was slower contralaterally (table 5). Thus in addition to effects on stability, fast movement asymmetries can be revealed in some cases before clinical signs are established.

(b) patients with established neurological deficits.

The patients in this group were those with clinical signs of pyramidal and motor cortex deficits. Finger movements were reduced and the most severely affected patients were hemiparetic.

Most patients in this group also showed an increase in stability contralateral to the lesion. This difference was less apparent with the eyes shut than open (table 6). As in the first group of patients the ipsilateral side was significantly less stable than the contralateral or the normal group. In the most severely affected patients motor control of their affected sides was almost impossible, and in these accuracy with the finger was then worse than in the ipsilateral side. In several patients there was a threshold effect. At

Table 5 Frequency of fast repetitive tapping with index finger

\begin{tabular}{lllc}
\hline & & \multicolumn{2}{l}{ Cortical lesion } \\
\cline { 3 - 4 } & & Ipsilateral & Contralateral \\
\hline All lesions & Mean & 2.93 & 2.34 \\
& SD & 0.67 & 0.54 \\
Lesions withoutMean & n 20 & 3.29 & $0.01>\mathrm{p}>0.001 \mathrm{t}=3.14$ \\
Clinical signs & SD & 0.74 & 0.32 \\
& $\mathrm{n}=5$ & \multicolumn{2}{c}{ Not significant } \\
\hline
\end{tabular}


Table 6 Amplitude of tremor in patients group 2, those with moderate neurological signs

\begin{tabular}{|c|c|c|c|c|c|}
\hline & & \multicolumn{4}{|c|}{$100 \mathrm{~g}$} \\
\hline & & Open & Shut & Open & Shut \\
\hline $\begin{array}{l}\text { Patients } \\
\text { Normals }\end{array}$ & $\begin{array}{l}\text { Mean } \\
\text { SD } \\
\text { n } \\
\text { Mean } \\
\text { SD } \\
\text { n }\end{array}$ & $\begin{array}{c}6.39 \\
3.05 \\
13 \\
4.83 \\
2.35 \\
18\end{array}$ & $\begin{array}{c}4.34 \\
2.06 \\
10\end{array}$ & $\begin{array}{c}9.09 \\
6.19 \\
13\end{array}$ & $\begin{array}{c}4 \cdot 20 \\
2 \cdot 78 \\
10\end{array}$ \\
\hline
\end{tabular}

"p" values from $t$ tests.

eyes open contralateral pts v normal $0.5>p>0.1$.

eyes shut ipsilateral pts v normal $0.02>p>0.01$.

patients eyes open contralateral $v$ ipsilateral NS.

patients eyes shut contralateral $v$ ipsilateral NS.

maintained forces of $80 \mathrm{~g}$ wt they were more stable in the side neurologically affected but as the force was reduced to 12.5 and $5 \mathrm{~g} \mathrm{wt}$ then the affected side became less accurate than the "normal" side.

The tremor profile, in terms of the frequencies of tremor present, was not normal ipsilaterally. The normal tremor profile was a peak at $1-3 \mathrm{~Hz}$ falling to background levels by around $7 \mathrm{~Hz}$. Little effect on the frequency of maximum tremor was found (table 7). However, in patients with established cortical lesions the tremor profile ipsilaterally showed a second peak at usually $6-7 \mathrm{~Hz}$ (fig 5). This pattern was seen in around $60 \%$ of patients with more severe clinical signs. When the amount of tremor at $6-7 \mathrm{~Hz}$ is compared with amount at the tremor peak at $1-3 \mathrm{~Hz}$, (see Method for data analysis technique), then it is shown that this second peak is slightly lower when compared with normals contralateral to the lesion but greatly increased ipsilateral to such lesions (table 8). Several cases of mature classical middle cerebral artery cerebrovascular accident, with hemiplegia, had an underlying but clear $6-7 \mathrm{~Hz}$ tremor in their ipsilateral hand when tested which was not apparent clinically (fig 6).

There did not appear to be a simple relation between the ipsilateral effect, time since the event or severity of deficit. It is important to establish, if possible, the origin of this effect. Of the 14 patients in the series all had had CT. In eight out of 10 with gliomas there was evidence of distortion of the brain so that midline structures were displaced by the tumour mass. Although there was no clinical evidence of a deficit in the ipsilateral limb to the lesion a subclinical effect could have been due to a mass effect on the thalamus or related areas. In those with an ipsilateral $6-7 \mathrm{~Hz}$ tremor in association with parietal tumours then the possible midline effect was much smaller than in frontal lesions. In at least three patients there was no CT evidence of any midline effect.
Some patients with frontoparietal gliomas who did not have the $6-7 \mathrm{~Hz}$ peak ipsilaterally prior to surgery were found to have developed one after operation associated with a worsening of their neurological deficit. In these patients it is difficult to postulate that surgical decompression increased the damage to midline structures. In other patients in whom the task was performed on several occasions during a progressive neurological disease the ipsilateral $6-7 \mathrm{~Hz}$ tremor increased. This ipsilateral tremor peak does not have to be associated with bilateral cortical or thalamic damage.

\section{Discussion}

Underlying all the conclusions in this paper is the assumption that the lesions of the patients have been in the area of or just below the sensorimotor cortex. Even with the use of CT precise localisation is not possible. In one patient with a parasagittal glioma on CT, an effect was seen in finger movements the control of which by the cortex is assumed to have been several cms away. This suggests that such gliomas may have infiltrated some distance beyond their apparent anatomical extent, and this makes the use of CT to assess the extent of a tumours affect a problem. However, in this paper the sizes of tumours which gave the effects on finger stability were smallest in the region of the sensorimotor cortex and largest in the frontal tumours. In several patients these effects were not seen in occipital tumours of comparative size.

This method of assessing motor control to the fingers under isometric conditions has revealed asymmetries in stability in the index fingers of patients with unilateral cortical and subcortical frontoparietal lesions before those lesions have lead to clinical deficits or when these deficits are still subtle. The main effect shown was a decrease in stability in the side ipsilateral to the lesion. In a group of patients more severely affected and manifesting clinical signs then the effect on stability was still observed but in addition a peak of

Table 7 Frequency of maximum tremor

\begin{tabular}{|c|c|c|c|c|c|}
\hline & & \multicolumn{4}{|c|}{ Cortical lesion } \\
\hline & & \multicolumn{2}{|c|}{ Ipsilateral } & \multicolumn{2}{|c|}{ Contralateral } \\
\hline & & Open & Shut & Open & Shut \\
\hline $\begin{array}{l}\text { Patients in group } 1 \\
\text { Patients in group } 2\end{array}$ & $\begin{array}{l}\text { Mean } \\
\text { SD } \\
\mathbf{n} \\
\text { Mean } \\
\text { SD } \\
\mathbf{n}\end{array}$ & $\begin{array}{l}1 \cdot 81 \\
0.34 \\
18 \\
1 \cdot 51 \\
0 \cdot 21 \\
11 \\
\text { Right }\end{array}$ & $\begin{array}{l}2 \cdot 13 \\
0 \cdot 52 \\
15 \\
2 \cdot 08 \\
0 \cdot 40 \\
9\end{array}$ & $\begin{array}{c}1 \cdot 76 \\
0 \cdot 39 \\
18 \\
1 \cdot 71 \\
0 \cdot 37 \\
11\end{array}$ & $\begin{array}{l}1.97 \\
0.66 \\
15 \\
1.90 \\
0.43 \\
8 \\
\text { Left }\end{array}$ \\
\hline Normal control & $\begin{array}{l}\text { Mean } \\
\text { SD } \\
\mathbf{n}\end{array}$ & $\begin{array}{r}1 \cdot 45 \\
0 \cdot 27 \\
19 \text { all }\end{array}$ & $\begin{array}{l}1.96 \\
0.52\end{array}$ & $\begin{array}{l}1.48 \\
0.26\end{array}$ & $\begin{array}{l}2.02 \\
0.43\end{array}$ \\
\hline
\end{tabular}



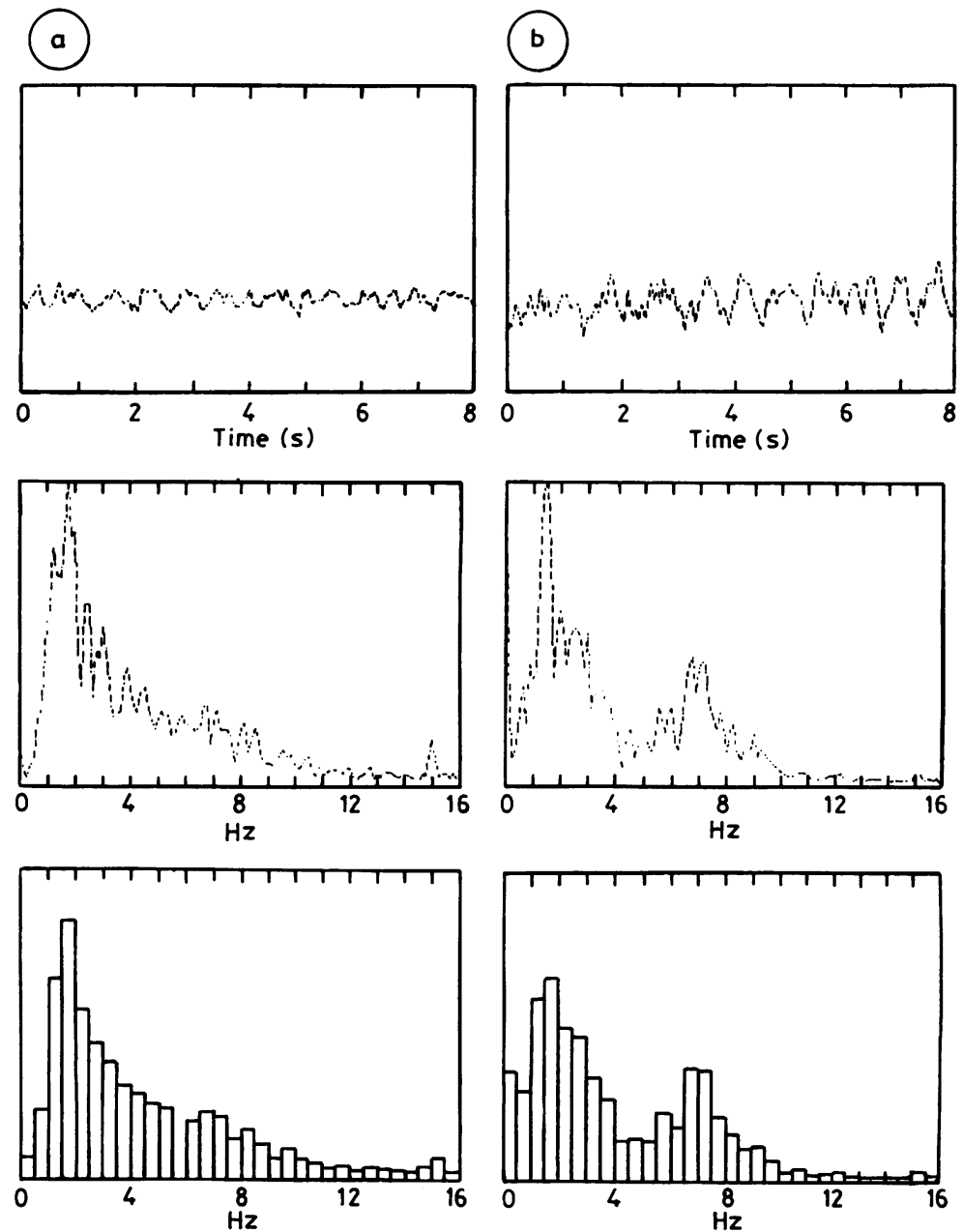

Fig 5 FFT print out of a patient from group 2 with a frontoparietal lesion to show the ipsilateral 6-7Hz peak. This peak was quantified by taking the amount of tremor in the $1 \mathrm{~Hz}$ period 6-7Hz from the histogram and comparing it with that found on the contralateral side and in the same 6-7Hz period in the normal controls. Sensitivity $100 \mathrm{gV}-1$. (a) ipsilateral to lesion, (b) contralateral to lesion.

Table 8 Amount of tremor at 6-7Hz compared with that at $1-2 \mathrm{~Hz}$ in patient with unilateral frontoparietal lesions

(a) Tremor at 6-7Hz as a percentage of that at $1-2 \mathrm{~Hz}$.

$$
\begin{aligned}
& \text { Ipsilateral } \frac{6-7 \mathrm{~Hz}}{1-2 \mathrm{~Hz}} \quad \text { Contralateral } \frac{6-7 \mathrm{~Hz}}{1-2 \mathrm{~Hz}} \\
& \begin{array}{lll}
\text { Normals n }=18 & \begin{array}{c}
18.8 \\
\text { Patients n }=13
\end{array} & 18.8 \\
& \text { SD } 84.46 & \\
& \text { SD 11.0 } & 16.8
\end{array}
\end{aligned}
$$

(b) Tremor at 6-7Hz in absolute amounts (g). $\begin{array}{llll}\text { Patients n }=13 & 4.68 \mathrm{~g} \quad \mathrm{p}>0.001 & 1.66 \mathrm{~g}\end{array}$ tremor was also seen at $6-7 \mathrm{~Hz}$ ipsilateral to the cortical lesion.

Ipsilateral effects on motor control at the elbow from unilateral frontoparietal lesions have been described by Colebatch, et $a l^{4}{ }^{4}$ who thought that the ipsilateral corticospinal tract might be possible. Such a pathway has been demonstrated physiologically to have an effect on H-reflex excitability in forearm muscles albeit at levels sub-threshold for direct muscle activation. ${ }^{5}$ Brodal $^{6}$ suffered a pure motor stroke leading to a left hemiplegia. He was surprised to find in the acute stages of his illness that, although there was 

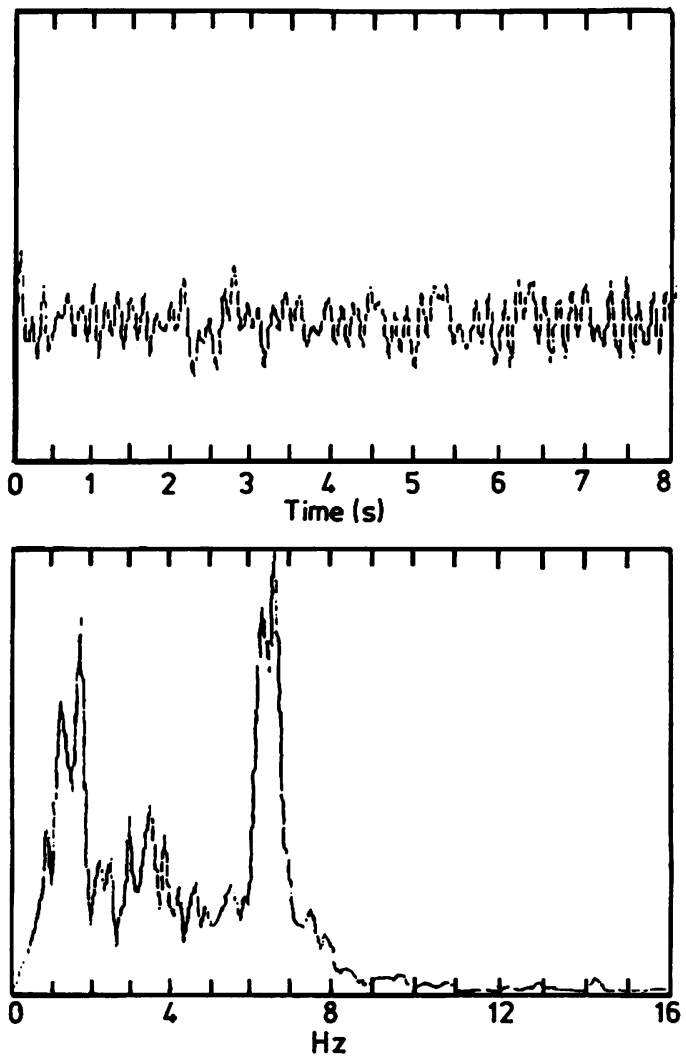

Fig 6 FFT print out of a patient with a left hemiplegia following a classical right middle cerebral artery $C V A$ two years previously. Right index finger $100 \mathrm{gV}-1$. Amplitude of tremor $9.6 \mathrm{~g}$. Frequency of maximum amplitude $6.63 \mathrm{~Hz}$. Note the underlying $6 \mathrm{~Hz}$ tremor in the clinically unaffected hand.

no dysgraphia, his writing with his dominant right hand was affected. He considered that there must be bilateral representation of movements of the hand at some level within the nervous system. He thought that such a precise task was likely to be under cerebellar control, discussed evidence for this, and concluded that the cerebellum was unlikely to be involved in motor control solely ipsilaterally.

The present work does not allow any conclusions on the pathways involved and in any case performance of such a task is likely to involve many such areas in an integrated manner. In a series of patients with unilateral cerebellar lesions finger stability in the present test was decreased contralaterally, ${ }^{7}$ again the reverse of the expected finding, but perhaps evidence for the involvement of a cerebro-cerebellar pathway in the cortical effect observed.
The apparent absence on an effect on the fingers contralateral to the lesion is also difficult to explain. Whilst some of the patients were clinically unaffected most had minor signs in the contralateral limb and so some effect would have been expected. That the motor cortex is involved in such small isometric movements, and that the smaller pyramidal tract cells are especially active during such tasks, has been shown. ${ }^{8}$

Although the motor cortex is involved in precise adjustments of position, when its function is compromised alternative structures may compensate. The motor cortex may be particularly involved in fine movements rather than commands to stay still. A deficit was revealed in these patients contralaterally in fast repetitive tapping.

The motor deficit in these patients might be dissected such that during isometric tasks the ipsilateral side might be affected whilst in tasks involving skilled and minute movements the contralateral side would show a deficit. At extremes of accuracy and stability the strict division of the neural axis for motor control across the midline, (cerebrum contralateral, cerebellum ipsilateral), may represent an oversimplification.

We thank the neurologists and neurosurgeons of the Wessex Neurological Centre for allowing us to perform the test on their patients and Dr EH Burrows for the neuroradiological assessment.

\section{References}

1 Cole JD, Philip HI, Sedgwick EM. The effect of small frontoparietal cortical lesions on digit tremor in man. J Physiol (Lond) 1985a;367:41P.

2 Cole JD, Philip HI, Sedgwick EM. An effect of unilateral frontoparietal cortical lesions on ipsilateral as well as contralateral digit tremor in man. J Physiol (Lond) 1985b;371:53P.

3 McGregor JJ, Watt AH. Pascal for Science and Engineering 1983, Pitman, London.

4 Colebatch JG, Gandevia SC, Spira PJ. Voluntary muscle strength in hemiparesis: distribution of weakness at the elbow. J Neurol Neurosurg Psychiatry 1986;49:1019-24.

5 Cowan JMA, Day BL, Marsden CD, Rothwell JC. Evidence for an ipsilateral corticospinal pathway to forearm muscles in man. J Physiol (Lond) 1983; 343:114P-115P.

6 Brodal A. Self-observations and neuro-anatomical considerations after a stroke. Brain, 1973;96:675-94.

7 Cole JD, Philip HI, Sedgwick EM. Stability and tremor in the fingers associated with cerebellar tract lesions in man. Submitted to J Neurol Neurosurg Psychiatry.

8 Evarts EV, Fromm C, Kroller J, Jennings VA. Motor cortex control of finely graded forces. J Neurophysiol 1983;49:1199-215. 